Original Research Paper

\title{
Modulation of IFN- $\gamma$, IL-4 and IL-17 Cytokines is Related to Parasitemia Control in Mice Infected by Trypanosoma cruzi and Treated with Biotherapy
}

\author{
${ }^{1}$ Fabiana Nabarro Ferraz, ${ }^{1}$ Franciele Karina da Veiga, ${ }^{1}$ Denise Lessa Aleixo, ${ }^{2}$ Suelen Santos da Silva, \\ ${ }^{2}$ Ivete Conchon-Costa, ${ }^{2}$ Wander Rogério Pavanelli and ${ }^{1}$ Silvana Marques de Araújo \\ ${ }^{I}$ Department of Basic Health Science, Laboratory of Parasitology, \\ Universidade Estadual de Maringá, Maringá, PR, Brazil \\ ${ }^{2}$ Department of Pathological Sciences, Laboratory of Experimental Immunoparasitology, \\ Universidade Estadual de Londrina, Londrina, PR, Brazil
}

Article history

Received: 03-08-2015

Revised: $19-08-2015$

Accepted: 08-09-2015

Correspondence Address:

Fabiana Nabarro Ferraz Department of Basic Health

Science, Laboratory of

Parasitology, Universidade

Estadual de Maringá, Maringá,

PR, Brazil,

Tel: +55-44-30114918,

$+55-44-30118985$,

Fax: +55-44-30115941

E-mail: fabiana_nabarro@hotmail.com

\begin{abstract}
The study of biotherapies as an intervention in experimental models of infection is a possible means to understand the effects of these highly diluted medications. The present study evaluated the immunological and parasitological effects of biotherapies that were prepared from mouse serum that was uninfected (sarcode: $\mathrm{BSNI}_{13 \mathrm{cH}}$ group) and chronically infected with the $\mathrm{Y}$ strain of $T$. cruzi (nosode: $\mathrm{BSI}_{13 \mathrm{cH}}$ group), dynamization $13 \mathrm{cH}$, in male Swiss mice at 28 days of age. On days 0 and 12 after infection (a.i.), the $\mathrm{BSNI}_{13 \mathrm{cH}}$ group exhibited a pronounced $\mathrm{Th} 1$ response that was attributable to a reduction of interleukin-4 (IL-4) concentrations, with no significant differences in interferon- $\gamma($ IFN $-\gamma)$ concentrations and a decrease in IL-17A concentrations on day 0 a.i. compared with the control and $\mathrm{BSI}_{13 \mathrm{cH}}$ groups. However, this cytokine balance was not sufficient to alter blood parasitemia in treated animals, likely because of a decrease in IFN- $\gamma$ concentrations on day 8 a.i., thus hindering a more effective Th1 response. In contrast, the $\mathrm{BSI}_{13 \mathrm{cH}}$ group presented a pronounced $\mathrm{Th} 2$ response that was attributable to an increase in IL- 4 concentrations (on days 0 and 8 a.i.) and a decrease in IFN- $\gamma$ concentration (on day 12 a.i.) compared with the control and $\mathrm{BSNI}_{13 \mathrm{cH}}$ groups. This cytokine balance suppressed the immune response to T. cruzi in murine infection, resulting in a significant increase in blood parasitemia, decrease in the patent period and subsequently a decrease in survival time. The results indicate that these highly diluted medications differentially modulate the immune system and represent a substantial contribution to the field of homeopathic medicine, providing evidence of the action of these medications.
\end{abstract}

Keywords: Trypanosoma cruzi, Animal Model, Biotherapy, Cytokines, Parasitemia

\section{Introduction}

Chagas disease was first described in 1909 by Carlos Chagas. It is caused by the parasite Trypanosoma cruzi and affects 7-8 million people worldwide, mostly in Latin America (WHO, 2005). However, no totally effective drugs have been developed to date for the etiological treatment of this disease (Coura and Dias, 2009; Guedes et al., 2011). The pathogenesis of Chagas disease is a consequence of the complex relationship between the parasite and immune-mediated mechanisms that is established during the acute phase of the infection (Dutra et al., 2014) and defined by susceptibility of the host species (Araújo-Jorge and Castro, 2000). Currently, many studies have demonstrated the biological effects of highly diluted medications on parasitic infections (Aleixo et al., 2014). Bellavite et al. (2007) suggested that these medications can regulate inflammatory and immunopathological processes, the neuroendocrine network and peripheral receptors. 
Biotherapies are highly diluted medications that are prepared from biological products (e.g., secretions, excretions, tissues, organs and products of microbial or allergen origin) according to homeopathic techniques. These preparations may have a pathological (nosode) or non-pathological (sarcode) origin (Brasil, 2011). The use of biotherapies as an intervention in murine infection with $T$. cruzi is a possible means to understand the effects of these highly diluted medications (Aleixo et al., 2012), since murine infection has been intensively studied and the mechanisms of resistance or susceptibility to infection have been sufficiently reported (Araújo-Jorge and Castro, 2000).

Previous studies have investigated the prophylactic and therapeutic effects of biotherapies in acute murine infection by this protozoan. These studies reported mainly parasitological, clinical, histopathological and hematological effects (Aleixo et al., 2012; Almeida et al., 2008; Ferraz et al., 2011, 2014a; Queiroz et al., 2006; Sandri et al., 2015). However, only a few studies have directly investigated the immunomodulatory effects of biotherapies against T. cruzi infection (Almeida et al., 2008; Ferraz et al., 2014b; Queiroz et al., 2006; Sandri et al., 2015). Almeida et al. (2008) and Queiroz et al. (2006) reported higher immunoglobulin $\mathrm{G}(\mathrm{IgG})$ production in mice that were treated before infection with a biotherapy that was prepared from trypomastigotes of $T$. cruzi (i.e., T. cruzi biotherapy), dynamizations $12 \mathrm{dH}$ and $30 \mathrm{dH}$, respectively. Sandri et al. (2015) reported a decrease in serum transforming growth factor $\beta$ (TGF- $\beta$ ) concentrations, an increase in the number of apoptotic cells and a decrease in hepatic inflammation in Swiss mice ( 56 days of age) that were treated after infection with $T$. cruzi biotherapy $17 \mathrm{dH}$. Ferraz et al. (2014b) reported a decrease in serum interleukin-4 (IL-4) and IL$17 \mathrm{~A}$ concentrations, without significant changes in tumor necrosis factor $\alpha$ (TNF- $\alpha$ ) or interferon- $\gamma$ (IFN- $\gamma$ ) concentrations, in Swiss mice that were treated after infection with a biotherapy that was prepared from healthy rabbit blood serum $13 \mathrm{cH}$.

These outcomes have stimulated investigations of biotherapies that are prepared from different active ingredients. We developed novel biotherapies that were prepared from Swiss mouse serum that was uninfected (sarcode) and chronically infected with T. cruzi (nosode). Blood serum contains, a priori, substances that are representative of all organic reactions (Lorenzi, 2006), performed to maintain homeostasis in the whole system that constitutes a complex biological organism. Thus, mice that are not infected with parasites, derived from known breeding stocks, can constitute a source of uninfected blood serum that provides information about "equilibrium patterns" (Galesanu, 2014; Horta, 2012). Blood serum from mice that are infected with $T$. cruzi can constitute a source of information on the immune response against infection, presenting antibodies, cytokines and others molecules that are produced by the immune response. Importantly, Swiss mice are highly susceptible to $\mathrm{Y}$ strain of T. cruzi (Araújo-Jorge and Castro, 2000) and the pattern of responses that these mice present reflects a highly susceptible species.

The present study evaluated the immunological and parasitological effects of biotherapies that were prepared from mouse serum that was uninfected (sarcode) and chronically infected with T. cruzi (nosode), dynamization $13 \mathrm{cH}$, in an acute murine model of infection by this protozoan.

\section{Materials and Methods}

\section{Ethics}

The study was approved by the Ethics Committee for Experiments in Animals of Universidade Estadual de Maringá (UEM; protocol no. 080/2012). All of the recommendations of National Law no. 11794 (October 8,2008 ) for the scientific management of animals were followed (Brasil, 2008).

\section{Animals and Infection}

Sixty-eight male Swiss mice, 28 days of age, were supplied by the Central Vivarium, UEM. The animals were from a conventional lineage with periodically controlled intestinal parasites and ectoparasites. The mice were maintained in the Parasitology Vivarium, UEM, under controlled temperature $\left(22 \pm 2^{\circ} \mathrm{C}\right)$ and a $12 \mathrm{~h} / 12 \mathrm{~h}$ light/dark cycle. The animals received food and water ad libitum.

The mice were intraperitoneally inoculated with 1,400 blood trypomastigotes of the Y strain of T. cruzi (Silva and Nussenzweig, 1953). The Y strain (Discrete Typing Units $T$. cruzi II) is one of the strains that are most used in experimental studies and has widely known biological and molecular properties (Brener, 1965; Melo and Brener, 1978; Zingales et al., 2009).

\section{Experimental Design and Treatment Regimen}

Blind, controlled and randomized trials were performed twice. To blind the experiments, each experimental group received a code so that the researchers were unaware of the treatment that was received by each group. The mice were divided into four experimental groups $(n=12-19$ animals/group; 12 animals/group for the analysis of immunological parameters and 7 animals/group for the analysis of parasitological parameters): UI (uninfected; $n=12$ ), IC (infection control; the animals were treated 2 days before infection and on days 2, 5 and 8 after infection [a.i.] with a $7 \%$ alcohol solution [medication vehicle], $\mathrm{n}=19$ ), $\mathrm{BSNI}_{13 \mathrm{cH}}$ (the animals were treated 2 days before infection and on days 2,5 and 8 a.i. with a biotherapy that was prepared from mouse serum that was uninfected with $T$. cruzi, dynamization $13 \mathrm{cH}, \mathrm{n}=19$ ) and $\mathrm{BSI}_{13 \mathrm{cH}}$ (animals were treated 2 days before infection and on days 2 , 
5 and 8 a.i. with a biotherapy that was prepared from mouse serum that was chronically infected with $T$. cruzi, dynamization $13 \mathrm{cH}, n=19$ ).

The medications were diluted in water $(10 \mu \mathrm{L} / \mathrm{mL})$ and offered ad libitum in a sterile amber bottle according to Aleixo et al. (2012) for 16 consecutive hours (medications were available to the animals from 5:00 PM to 9:00 AM). The treatment regimen was based on the actions of the medication that are linked to immunomodulatory effects on the specific evolution of the $\mathrm{Y}$ strain of $T$. cruzi in Swiss mice. Thus, this treatment regimen assessed the actions of the biotherapy and immune system before and after the presence of the parasite (Aleixo et al., 2012).

\section{Preparation of the Biotherapies (sarcode and nosode)}

The biotherapies were produced from mouse serum that was uninfected (sarcode) and chronically infected with $T$. cruzi (nosode). Six male Swiss mice, 56 days of age, were supplied by the Central Vivarium, UEM. The mice were divided into two groups ( $n=3$ animals/group; uninfected and infected with the Y strain of T. cruzi) and maintained in the Parasitology Vivarium, UEM, under controlled conditions. The infected group was intraperitoneally inoculated with 50,000 blood trypomastigotes of the Y strain of $T$. cruzi (Silva and Nussenzweig, 1953). Blood parasitemia of the mice was evaluated daily and chronic infection (i.e., subpatent parasitemia and the survival of infected animals) was obtained with five doses of benznidazole (LAFEPE, Pernambuco, Brazil; three $100 \mathrm{mg} / \mathrm{kg}$ doses on days 11 , 14 and 19 a.i.; three $250 \mathrm{mg} / \mathrm{kg}$ doses on days 13,16 and 22 a.i) via oral gavage. Four months after infection, 500 $\mu \mathrm{L}$ of blood of each animal was aseptically collected from the orbital plexus and mixed in a sterile tube. The blood of the uninfected animals was collected on the same day, $500 \mu \mathrm{L}$ of blood of each animal also was aseptically collected from the orbital plexus and mixed in other sterile tube. After blood clotting, the samples were centrifuged at 3000 rotations per minute (rpm) for $10 \mathrm{~min}$ and sera were collected under sterile conditions (laminar flow hood), stored at $-20^{\circ} \mathrm{C}$ and subsequently used for the preparation of the medications.

The biotherapies were prepared in a laminar flow hood on a centesimal scale $(\mathrm{cH})$ until dynamization $13 \mathrm{cH}$, according to the Brazilian Homeopathic Pharmacopoeia, 3rd edition (Brasil, 2011). This latter preparation was made in a $7 \%$ alcohol solution for the animal treatments and stored in sterile amber glass flasks. Rhythmic agitations between dilutions were performed using a Denise 10-50 mechanical stirrer (AUTIC, Campinas, Brazil). Dynamization $13 \mathrm{cH}$ was chosen based on the beneficial results reported by Falkowski et al. (2012), who evaluated the effects of highly diluted medications using the same experimental model.

Microbiological tests (Microbiology Laboratory, UEM) of the inert ingredients were negative according to regulations of the Brazilian Ministry of Health - RDC no. 67 (Brasil, 2007).

\section{Immunological Parameters}

On days 0,8 and 12 a.i., peripheral blood was collected from four animals per group. The UI group provided the basal levels of cytokines. After blood clotting, the samples were centrifuged at $3000 \mathrm{rpm}$ for $10 \mathrm{~min}$ and sera were separated and stored at $-20^{\circ} \mathrm{C}$ (Gholamnezhad et al., 2014) for subsequent cytokine determination.

The levels of IFN- $\gamma$, IL-4 and IL-17A were determined by an enzyme-linked immunosorbent assay according to the manufacturer's instructions (eBiosciencesR, San Diego, CA, USA). Plates were read at $450 \mathrm{~nm}$ using a Multiskan GO reader (Thermo Scientific, Waltham, USA).

\section{Parasitological Parameters}

Parasitemia was assessed using Brener's technique (Brener, 1962). The parasite count was performed daily from day 4 a.i. until death of the animals. The parasitemia curve was plotted using the mean of parasitemia in each group. Based on the parasitemia curve, we determined the prepatent period (i.e., the mean time, in days, between inoculation and the day when fresh blood was positive), patent period (i.e., the mean time, in days, that parasitemia was detected in fresh blood), parasitemia peak (i.e., the highest mean parasitemia observed in fresh blood), total parasitemia (i.e., the mean of the sum of parasitemia of each mouse over the entire experiment), mortality rate (i.e., the total number of dead animals relative to the number of infected animals) and survival time (i.e., the mean time that the animals survived, in days).

\section{Statistical Analysis}

The data were statistically analyzed using BioEstat 5.0 software (Civil Society Mamirauá, Belém, PA, Brazil) at a $5 \%$ level of significance using analysis of variance (ANOVA). Differences between samples were determined by the Least Significant Difference (LSD) test.

\section{Results}

\section{Immunological Parameters}

During the course of infection (comparison among the evaluated days 0,8 and 12 a.i.), the groups presented different evolutions of serum IFN- $\gamma$ levels (Fig. 1). The IC group presented a significant increase in IFN- $\gamma$ 
concentrations on day $8(p<0.001)$ and day $12(p<0.001)$ a.i. compared with day 0 . The $\mathrm{BSNI}_{13 \mathrm{cH}}$ group presented a significant increase in IFN- $\gamma$ concentrations on day 12 a.i compared with day $0(p<0.001)$ and day $8(p<0.001)$ a.i. The $\mathrm{BSI}_{13 \mathrm{cH}}$ group exhibited a significant increase in IFN- $\gamma$ concentrations on day 8 a.i compared with day $0(p<0.001)$ and a subsequent decrease on day 12 a.i. compared with day 8 a.i. $(p<0.001)$. On day 0 , no significant difference was observed among groups $(p>0.05)$. On day 12 a.i., the $\mathrm{BSNI}_{13 \mathrm{cH}}$ group exhibited IFN- $\gamma$ concentrations that were significantly lower compared with the IC group $(p<0.001)$ and $\mathrm{BSI}_{13 \mathrm{cH}}$ group $(p<0.001)$, but these values were not different from the basal value (UI group; $p>0.05$ ). On day 12 a.i., the $\mathrm{BSI}_{13 \mathrm{cH}}$ group presented lower IFN- $\gamma$ concentrations compared with the IC group $(p<0.01)$ and $\mathrm{BSNI}_{13 \mathrm{cH}}$ group $(p<0.001)$, but these values were higher than the basal value $(p<0.01$; Fig. 1$)$.

The $\mathrm{BSNI}_{13 \mathrm{cH}}$ and $\mathrm{BSI}_{13 \mathrm{cH}}$ groups exhibited a different evolution of serum IL-4 levels during the course of infection (Fig. 2). The IC group did not present significant changes in IL-4 concentrations during the days of assessment $(p>0.05)$ and the IL-4 concentrations were not different from basal values $(p>0.05)$. The $\mathrm{BSNI}_{13 \mathrm{cH}}$ group also did not present significant changes in IL-4 concentrations during the days of assessment $(p>0.05)$, but these values on days 0,8 and 12 a.i. were lower than the basal value $(p<0.01, p<0.01$ and $p<0.001$, respectively), IC group $(p<0.01, p<0.001$ and $p<0.001$, respectively) and $\mathrm{BSI}_{13 \mathrm{cH}}$ group $(p<0.001, p<0.001$ and $p<0.001$, respectively). During the course of infection, the $\mathrm{BSI}_{13 \mathrm{cH}}$ group presented a significant decrease in IL-4 concentrations on day $8(p<0.01)$ and day $12(p<0.01)$ a.i. compared with day 0 . However, on days 0 and 8 a.i., the $\mathrm{BSI}_{13 \mathrm{cH}}$ group exhibited higher IL-4 concentrations compared with the basal value $(p<0.01$ and $p<0.05$, respectively), IC group $(p<0.01$ and $p<0.05$, respectively) and $\mathrm{BSNI}_{13 \mathrm{cH}}$ group $(p<0.001$ and $p<0.001$, respectively). On day 12 a.i., the $\mathrm{BSI}_{13 \mathrm{cH}}$ group did not present significant differences in IL-4 concentrations compared with the basal value or IC group (both $p>0.05$; Fig. 2).

The $\mathrm{BSNI}_{13 \mathrm{cH}}$ and $\mathrm{BSI}_{13 \mathrm{cH}}$ groups did not have significantly different IL-17A concentrations during the course of infection ( $p>0.05$; Fig. 3$)$. The IC group presented a significant decrease in IL-17A concentrations on day 8 a.i. compared with day 0 $(p<0.05)$. On day 0 , the $\mathrm{BSNI}_{13 \mathrm{cH}}$ group presented lower IL-17A concentrations compared with the basal value $(p<0.01)$, IC group $(p<0.01)$ and $\mathrm{BSI}_{13 \mathrm{cH}}$ group $(p<0.05)$. On day 8 a.i., the $\mathrm{BSNI}_{13 \mathrm{cH}}$ and IC groups exhibited lower IL-17A concentrations compared with the basal value $(p<0.05)$ and $\mathrm{BSI}_{13 \mathrm{cH}}$ group $(p<0.05)$. On day 12 a.i., no significant difference was observed among groups ( $p>0.05$; Fig. 3 ).

The IFN- $\gamma /$ IL-4 ratio was calculated to evaluate the Th1/Th2 cytokine balance (Fig. 4). On days 0 and 12 a.i., the $\mathrm{BSNI}_{13 \mathrm{cH}}$ group exhibited significant increases in the IFN- $\gamma /$ IL- 4 ratio compared with the IC and $\mathrm{BSI}_{13 \mathrm{cH}}$ groups $(p<0.001)$, with a more pronounced Th1 response that was attributable to a reduction of IL-4 concentrations. However, on day 8 a.i., the $\mathrm{BSNI}_{13 \mathrm{cH}}$ group presented significant decreases in the IFN- $\gamma / \mathrm{IL}-4$ ratio compared with the IC and $\mathrm{BSI}_{13 \mathrm{cH}}$ groups $(p<0.01)$, attributable to a significant reduction of IFN- $\gamma$ concentrations.

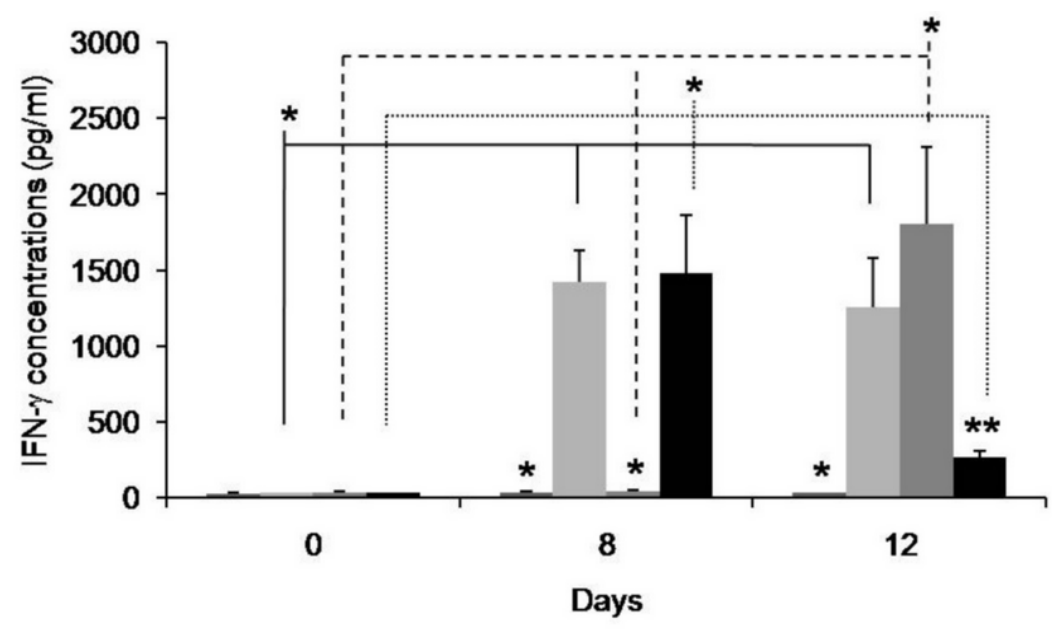

$\square \mathrm{UI} \approx \mathrm{IC} \backsim \mathrm{BSNI} \mathbf{1 3} \mathrm{cH} \quad \mathrm{BSI} \mathbf{1 3} \mathrm{cH}$

Fig. 1. Serum IFN- $\gamma$ concentrations ( $\mathrm{pg} / \mathrm{ml})$ assessed on days 0,8 and 12 after infection in Swiss mice, 28 days of age, infected with T. cruzi-Y strain belonging to the groups: UI (animals uninfected), IC (treated with 7\% alcohol solution), BSNI ${ }_{13 \mathrm{cH}}$ (treated with biotherapy of mouse serum uninfected with $T$. cruzi $13 \mathrm{cH}$ ) and $\mathrm{BSI}_{13 \mathrm{cH}}$ (treated with biotherapy of mouse serum chronically infected with $T$. cruzi $13 \mathrm{cH})$. *and $* *$ Statistical significance $p<0.05$ 


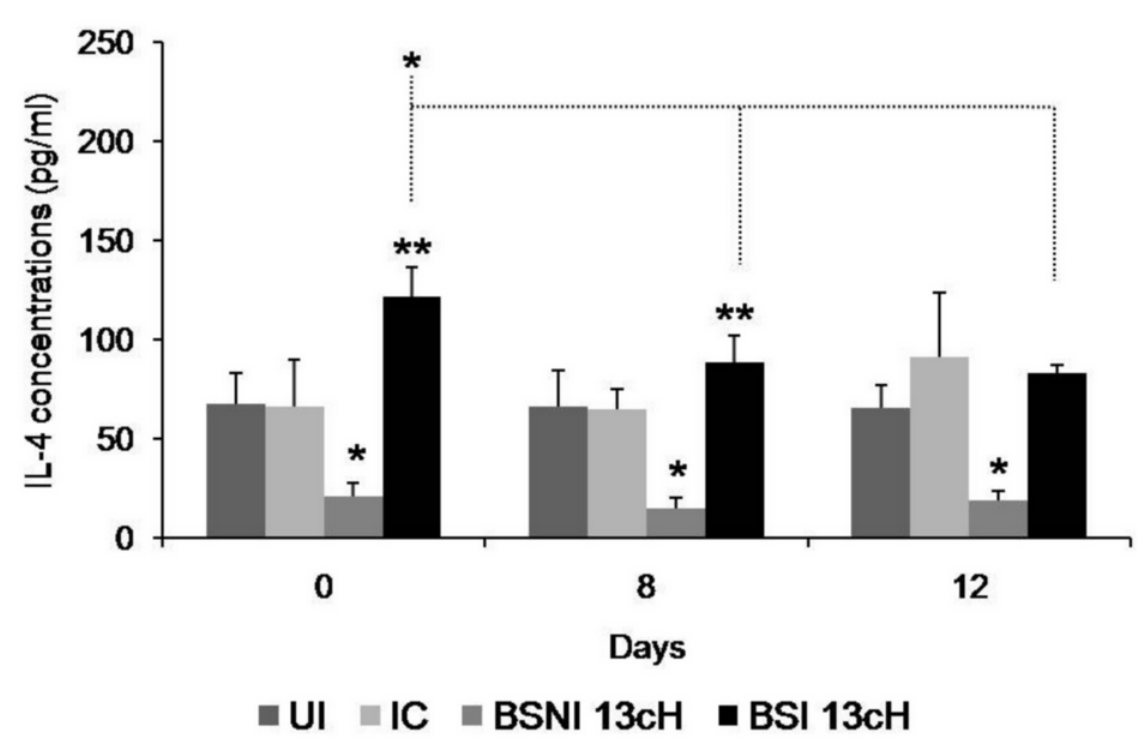

Fig. 2. Serum IL-4 concentrations ( $\mathrm{pg} / \mathrm{ml})$ assessed on days 0,8 and 12 after infection in Swiss mice, 28 days of age, infected with $T$. cruzi-Y strain belonging to the groups: UI (animals uninfected), IC (treated with 7\% alcohol solution), BSNI $13 \mathrm{cH}$ (treated with biotherapy of mouse serum uninfected with $T$. cruzi $13 \mathrm{cH}$ ) and $\mathrm{BSI}_{13 \mathrm{cH}}$ (treated with biotherapy of mouse serum chronically infected with $T$. cruzi $13 \mathrm{cH})$. *and ** Statistical significance $p<0.05$

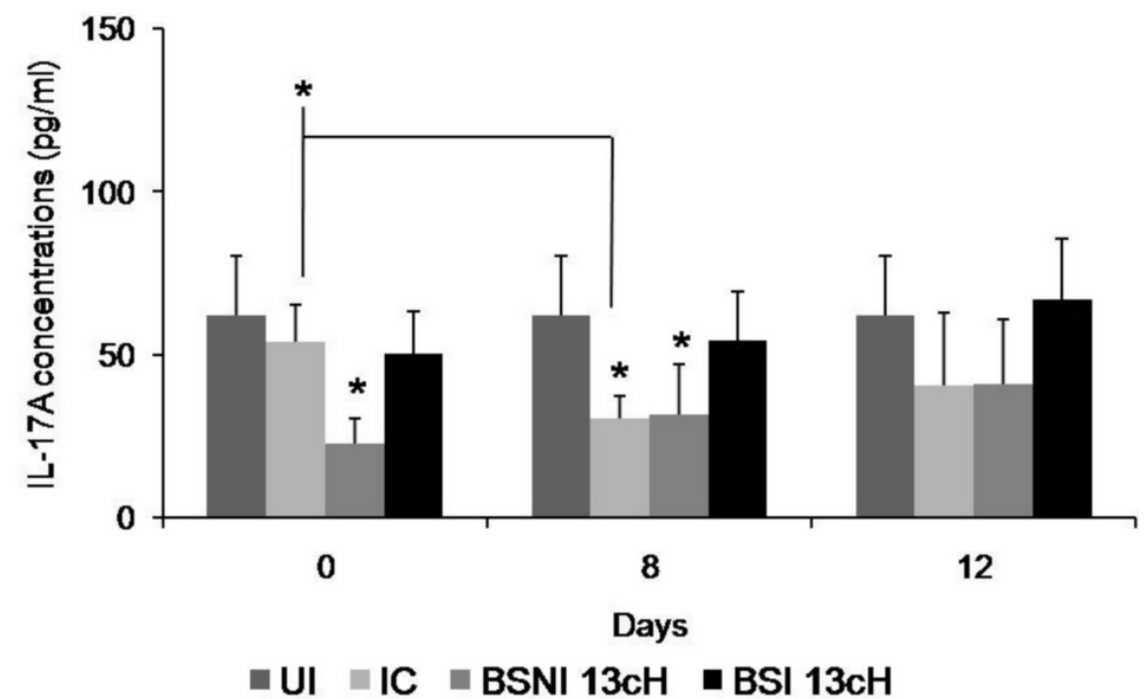

Fig. 3. Serum IL-17A concentrations (pg/ml) assessed on days 0,8 and 12 after infection in Swiss mice, 28 days of age, infected with $T$. cruzi-Y strain belonging to the groups: UI (animals uninfected), IC (treated with $7 \%$ alcohol solution), $\mathrm{BSNI}_{13 \mathrm{cH}}$ (treated with biotherapy of mouse serum uninfected with $T . c r u z i \quad 13 \mathrm{cH}$ ) and $\mathrm{BSI}_{13 \mathrm{cH}}$ (treated with biotherapy of mouse serum chronically infected with $T$. cruzi $13 \mathrm{cH})$. *Statistical significance $p<0.05$

In contrast, the $\mathrm{BSI}_{13 \mathrm{cH}}$ group exhibited a significant decrease in the IFN- $\gamma / \mathrm{IL}-4$ ratio on days 0 and 12 a.i. compared with the IC and $\mathrm{BSNI}_{13 \mathrm{cH}}$ groups $(p<0.01)$ and on day 8 compared with the IC group, with a more pronounced Th2 response that was attributable to an increase in IL-4 concentrations on days 0 and 8 a.i. and a decrease in IFN- $\gamma$ concentrations on day 12 a.i. (Fig. 4).

\section{Parasitological Parameters}

No significant differences were found in parasitological parameters between the $\mathrm{BSNI}_{13 \mathrm{cH}}$ and IC groups $(p>0.05)$. However, the mice in the $\mathrm{BSI}_{13 \mathrm{cH}}$ group exhibited significant increases in total parasitemia $(p<0.01)$ and parasitemia peak (day 11 a.i.; $p<0.05$ ) and decreases in the patent period $(p<0.01)$ and survival time $(p<0.01)$ compared with the IC group (Table 1). 


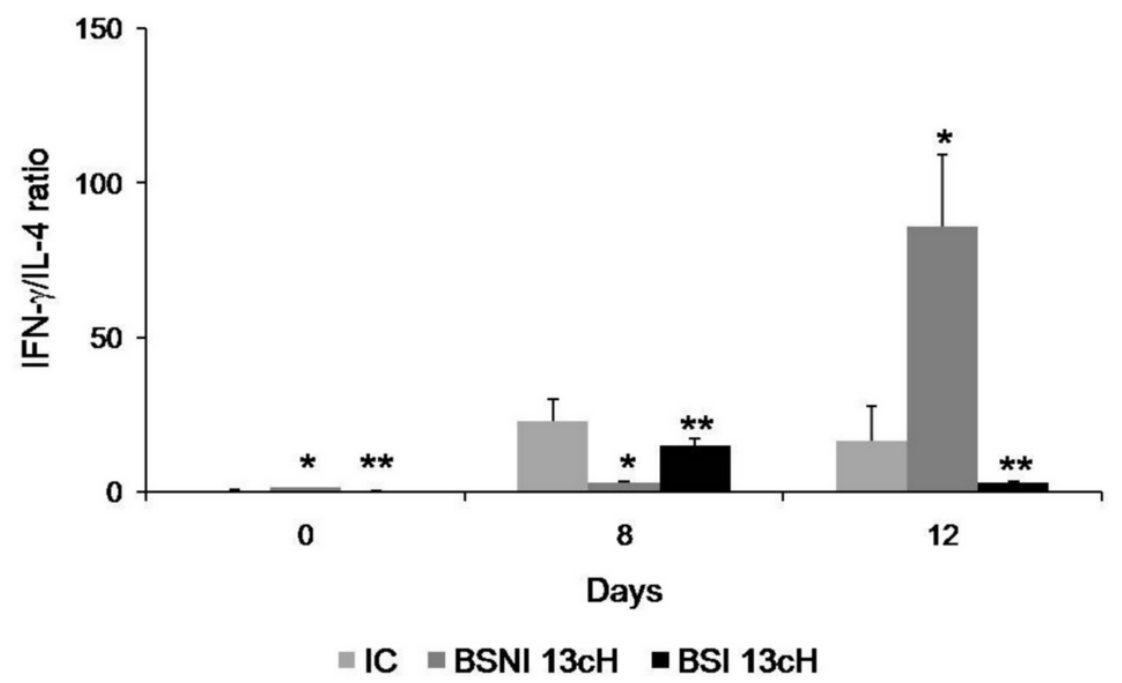

Fig. 4. IFN- $\gamma / \mathrm{IL}-4$ ratios (Th1/Th2 balance) obtained on days 0,8 and 12 after infection in Swiss mice, 28 days of age, infected with T. cruzi-Y strain belonging to the groups: IC (treated with $7 \%$ alcohol solution), $\mathrm{BSNI}_{13 \mathrm{cH}}$ (treated with biotherapy of mouse serum uninfected with $T$. cruzi $13 \mathrm{cH}$ ) and $\mathrm{BSI}_{13 \mathrm{cH}}$ (treated with biotherapy of mouse serum chronically infected with $T$. cruzi $13 \mathrm{cH})$. *and ** Statistical significance $p<0.05$

Table 1. Parasitological parameters (mean \pm standard deviation) assessed in groups of Swiss mice, 28 days of age, infected with $T$. cruzi-Y strain submitted to the treatment with biotherapies prepared from mouse serum

\begin{tabular}{lllllll}
\hline Groups & $\begin{array}{l}\text { Prepatent } \\
\text { period (days) }\end{array}$ & $\begin{array}{l}\text { Patent } \\
\text { period (days) }\end{array}$ & $\begin{array}{l}\text { Parasitemia peak } \\
\text { (trypomastgotes/mL) }\end{array}$ & $\begin{array}{l}\text { Total parasitemia } \\
(\text { trypomastigotes/ml) }\end{array}$ & $\begin{array}{l}\text { Survival } \\
(\text { days) }\end{array}$ & $\begin{array}{l}\text { Mortality } \\
(\%)\end{array}$ \\
\hline IC & $6.0 \pm 1.3$ & $13.0 \pm 2.3$ & $(9.5 \pm 12.1) \times 10^{5}$ & $(63.7 \pm 20.8) \times 10^{5}$ & $15.3 \pm 2.4$ & 100 \\
BSNI $_{13 \mathrm{cH}}$ & $5.8 \pm 1.0$ & $11.3 \pm 2.7$ & $(22.3 \pm 17.0) \times 10^{5}$ & $(100.0 \pm 56.4) \times 10^{5}$ & $13.7 \pm 2.4$ & 100 \\
BSI $_{13 \mathrm{cH}}$ & $5.8 \pm 1.7$ & $9.5 \pm 1.0 *$ & $(30.9 \pm 16.5) \times 10^{5} *$ & $(100.3 \pm 21.0) \times 10^{5} *$ & $12.0 \pm 0.0 *$ & 100 \\
\hline
\end{tabular}

*Statistical significance $(p<0.05)$ compared with the Infection Control (IC). IC- treated with $7 \%$ alcohol solution, $\mathrm{BSNI}_{13 \mathrm{cH}}-$ treated with biotherapy of mouse serum uninfected with $T$. cruzi $13 \mathrm{cH}$, and $\mathrm{BSI}_{13 \mathrm{cH}}$ - treated with biotherapy of mouse serum infected with $T$. cruzi $13 \mathrm{cH}$

\section{Discussion}

The present study assessed the effects of biotherapies that were prepared from mouse serum that was uninfected (sarcode) and chronically infected with $T$. cruzi (nosode), dynamization $13 \mathrm{cH}$, in a murine model of acute infection by this protozoan. The results showed that these highly diluted medications differentially modulated the immune system in Swiss mice that were infected with the Y strain of $T$. cruzi, producing different evolutions of infection.

The use of biotherapy that was prepared from mouse serum that was uninfected with $T$. cruzi $13 \mathrm{cH}\left(\mathrm{BSNI}_{13 \mathrm{cH}}\right.$ group) produced an immunomodulatory action that involved a significant decrease in IFN- $\gamma$ concentrations on day 8 a.i, IL-4 concentrations on days 0,8 and 12 a.i. and IL-17A concentrations on day 0 compared with the control and $\mathrm{BSI}_{13 \mathrm{cH}}$ groups. On day 8 a.i., the IL-17A concentrations were lower only compared with the $\mathrm{BSI}_{13 \mathrm{cH}}$ group, in which the IC group also presented a decrease in IL-17A concentrations on this day of assessment. Interestingly, the concentrations of IL-4 on days 0,8 and 12 a.i and IL-17A on days 0 and 8 were lower than the basal values that were measured in the UI group. Modulation obtained for these cytokines on day 0 was the result of the action of the medication that was administered $48 \mathrm{~h}$ before the animals were infected with the $\mathrm{Y}$ strain of $T$. cruzi.

The analysis of the Th1/Th2 balance in the $\mathrm{BSNI}_{13 \mathrm{cH}}$ group revealed increases in the IFN- $\gamma / \mathrm{IL}-4$ ratio on days 0 and 12 a.i., with a more pronounced Th1 response that was attributable to a reduction of IL-4 concentrations, with no significant differences in IFN- $\gamma$ concentrations compared with the IC and $\mathrm{BSI}_{13 \mathrm{cH}}$ groups. Although, on days 0 and 12 a.i. a Th1 response that is involved in protective actions against acute $T$. cruzi infection (Aliberti et al., 2001; Holscher et al., 1998; Silva et al., 1995) was more pronounced, on day 8 a.i. the $\mathrm{BSNI}_{13 \mathrm{cH}}$ group showed significant decreases in the IFN- $\gamma / \mathrm{IL}-4$ ratio because of the reduction in IFN- $\gamma$ concentrations compared with the IC and $\mathrm{BSI}_{13 \mathrm{cH}}$ groups. This cytokine balance was not sufficient to alter blood parasitemia in treated animals, likely because of the decrease in IFN- $\gamma$ concentrations on day 8 a.i., thus hindering a more effective Th1 immune response with a reduction of parasitemia.

In contrast, the use of a biotherapy that was prepared from mouse serum that was chronically infected with $T$. cruzi $13 \mathrm{cH}\left(\mathrm{BSI}_{13 \mathrm{cH}}\right.$ group) produced modulation that suppressed the immune response to $T$. cruzi. The 
immunomodulatory action involved a significant decrease in IFN- $\gamma$ concentrations on day 12 a.i. and an increase in IL-4 concentrations on days 0 and 8 a.i. compared with the $\mathrm{IC}$ and $\mathrm{BSNI}_{13 \mathrm{cH}}$ groups. Interestingly, IL-4 concentrations on days 0 and 8 a.i were higher than the basal values that were measured in the UI group. IL-17A concentrations were not different among the days of evaluation and also were not different compared with the IC and UI groups. The analysis of Th1/Th2 balance revealed a significant decrease in the IFN- $\gamma / \mathrm{IL}-4$ ratio on days 0,8 and 12 a.i., with a more pronounced $\mathrm{Th} 2$ response that was attributable to an increase in IL-4 concentrations on days 0 and 8 a.i. and a decrease in IFN- $\gamma$ concentrations on day 12 a.i. compared with the IC and $\mathrm{BSNI}_{13 \mathrm{cH}}$ groups. This cytokine balance was related to susceptibility in the acute phase of Chagas disease (Hiyama et al., 2001), resulting in significant increases in total parasitemia and parasitemia peak and decrease in the patent period due to decrease in survival time of the animals compared with the IC group.

Previous studies performed by our group assessed biotherapies that were prepared from rabbit serum that was uninfected (sarcode) and chronically infected with $T$. cruzi, dynamization $13 \mathrm{cH}$ (nosode), in the same experimental model. The use of a biotherapy that was prepared from rabbit serum that was uninfected with $T$. cruzi $13 \mathrm{cH}$ (sarcode) favored a pronounced Th1 response that was attributable to a reduction of IL-4 concentrations on days 8 and 12 a.i., associated with a decrease in IL-17A concentrations on day 12 a.i. This more balanced immunomodulation without significant variations in IFN- $\gamma$ concentrations had a beneficial effect in the host, with decreases in total parasitemia, parasitemia peak (Ferraz et al., 2014b) and parasite load/inflammation in the heart and an increase in survival time (Ferraz F.N., unpublished data). Moreover, the use of a biotherapy that was prepared from rabbit serum that was chronically infected with $T$. cruzi, dynamization $13 \mathrm{cH}$ (nosode), favored a pronounced $\mathrm{Th} 2$ response but only on day 12 a.i. The Th2 response was attributable to an increase in IL-4 concentration on day 12 a.i., with no significant difference in IFN- $\gamma$ concentrations and a decrease in IL-17A concentrations on day 12 a.i. compared with the control group. This cytokines balance, different from biotherapy that was prepared from mouse serum that suppressed the immune response to $T$. cruzi, did not alter the blood parasitemia in treated animals but decreased parasite load/inflammation in the heart, likely by promoting a more balanced $\mathrm{Th} 2$ response only on day 12 a.i., without significantly decreasing IFN- $\gamma$ concentrations (Ferraz F.N., unpublished data).

The Th17 response has been linked to the pathogenesis of several inflammatory/autoimmune diseases (Tesmer et al., 2008) and some infectious diseases (Matsuzaki and Umemura, 2007; Rutitzky and Stadecker, 2006). However, the pathogenic or protective role of the
Th17 response in mice or humans that are infected with T. cruzi is still controversial (Erdmann et al., 2013; Magalhães et al., 2013; da Matta Guedes et al., 2010; Miyazaki et al., 2010; Monteiro et al., 2007; Pérez et al., 2011). Some studies reported that the role of IL-17A in acute resistance to $T$. cruzi (Miyazaki et al., 2010) and the induction or action of IL-17A (which does or does not reduce parasitemia) appears to depend on the T. cruzi strain and mouse strain that are used as experimental models (Erdmann et al., 2013). Moreover, Pérez et al. (2011) found that IL-17 in human Chagas disease is enhanced in severe cardiac patients. In contrast, Magalhães et al. (2013) correlated lower IL-17 expression with worse cardiac function in human Chagas disease. Importantly, the cytokines that are produced in Chagas disease act in concert, the final balance of which is a determining factor in whether the development of pathological alterations is mild or aggressive.

According to the results of this and other studies (Almeida et al., 2008; Ferraz et al., 2014b; Queiroz et al., 2006; Sandri et al., 2015), one possibility is that one of the mechanisms by which these highly diluted medications exert their effects is by modulating the immune system. Additionally, the ways in which the host's immune system is modulated depends of the type of information that is provided by the species-specific serum that is used to prepare biotherapies, including health/homeostasis, disease/imbalance and resistance or susceptibility. The pattern of immunomodulation that was observed in this susceptible experimental model of infection with the $\mathrm{Y}$ strain of $T$. cruzi shows that biotherapies that are prepared from healthy serum primarily stimulate the Th1 response, with a decrease in IL-4 concentrations associated with a decrease in IL-17A concentrations, which was observed for both rabbit serum (Ferraz et al., 2014b) and mouse serum. This response, in turn, becomes more balanced and beneficial to the host when the serum is derived from a host that is more resistant to infection with $T$. cruzi (i.e., the rabbit) (Ferraz et al., 2014b). However, biotherapies that are prepared from serum that contains information on the immune reaction against $T$. cruzi stimulates primarily the Th2 response, with increases in IL-4 concentrations that become more intensive and harmful to the host when the serum is derived from a host that is susceptible to $T$. cruzi infection (i.e., Swiss mice). These results raise the issue of the effect of biotherapies that are prepared from healthy serum from animals that are refractory to $T$. cruzi infection.

\section{Conclusion}

In summary, the biotherapy that was prepared from mouse serum that was uninfected with $T$. cruzi $13 \mathrm{cH}$ (sarcode; $\mathrm{BSNI}_{13 \mathrm{cH}}$ group) caused a pronounced Th1 response on days 0 and 12 a.i. that was attributable to a reduction of IL-4 concentrations, with no significant differences in IFN- $\gamma$ concentrations and a decrease in IL17A concentrations on day 0 a.i. compared with the control 
and $\mathrm{BSI}_{13 \mathrm{cH}}$ groups. However, this cytokine balance was not sufficient to alter blood parasitemia in treated animals, likely because of a decrease in IFN- $\gamma$ concentrations on day 8 a.i., thus hindering a more effective Th1 response. In contrast, the biotherapy that was prepared from mouse serum that was chronically infected with $T$. cruzi $13 \mathrm{cH}$ (nosode; $\mathrm{BSI}_{13 \mathrm{cH}}$ group) caused a pronounced $\mathrm{Th} 2$ response that was attributable to an increase in IL- 4 concentrations on days 0 and 8 a.i. and a decrease in IFN- $\gamma$ concentrations on day 12 a.i. compared with the control and $\mathrm{BSNI}_{13 \mathrm{cH}}$ groups. This cytokine balance suppressed the immune response to $T$. cruzi in murine infection, resulting in a significant increase in blood parasitemia and decreases in the patent period and survival time. The results showed that these highly diluted medications differentially modulated the immune system in a mouse model of $T$. cruzi infection and may provide a substantial contribution to the field of homeopathic medicine by providing evidence of the action of these medications.

\section{Funding Information}

This work was supported by the Coordenação de Aperfeiçoamento de Pessoal de Nível SuperiorCAPES/PROAP [no. 68/7-1]; and Convênio Fundação Araucária-UEM [no. 251/12, protocol no. 22.390].

\section{Author's Contributions}

Fabiana Nabarro Ferraz: She designed the research plan and organized the study, participated in all experiments, coordinated the data-analysis and drafted the article.

Franciele Karina da Veiga and Denise Lessa Aleixo: They participated in all experiments and acquisition of data.

Suelen Santos da Silva, Ivete Conchon-Costa and Wander Rogério Pavanelli: They participated of the dosage of cytokines and acquisition of data.

Silvana Marques de Araújo: She was the advisor of the study, participated in the design of the study, interpretation of data and helped draft the article.

\section{Ethics}

This article is original and contains unpublished material. The corresponding author confirms that all of the other authors have read and approved the manuscript and no ethical issues involved.

\section{References}

Aleixo, D.L., F.N. Ferraz, E.C. Ferreira, M. de Lana and M.L. Gomes et al., 2012. Highly diluted medication reduces parasitemia and improves experimental infection evolution by Trypanosoma cruzi. BMC Res. Notes, 5: 352-352. DOI: 10.1186/1756-0500-5-352
Aleixo, D.L., L.V. Bonamin, F.N. Ferraz, F.K. da Veiga and S.M. de Araujo, 2014. Homeopathy in parasitic diseases. Int. J. High Dilution Res., 13: 13-27.

Aliberti, J.C., J.T. Souto, A.P. Marino, J. LannesVieira and M.M. Teixeira et al., 2001. Modulation of chemokine production and inflammatory responses in interferon-gamma and tumor necrosis factor-R1-deficient mice during Trypanosoma cruzi infection. Am. J. Pathol., 158: 1433-1440. DOI: 10.1016/S0002-9440(10)64094-1

Almeida, R.L., M.C.O. Campos, L.V.B Herrera., L.V. Bonamin and A.H. Fonseca, 2008. Effects of homeopathy in mice experimentally infected with Trypanosoma cruzi. Homeopathy, 97: 65-69. DOI: 10.1016/j.homp.2008.02.009

Araújo-Jorge, T.C. and S.L.D. Castro, 2000. Doença de Chagas: Manual para experimentação animal. Fio Cruz, Rio de Janeiro.

Bellavite, P., R. Ortolani, F. Pontarollo, G. Pitari and A. Conforti, 2007. Immunology and homeopathy. 5. The rationale of the 'simile'. Evid. Based Complement. Alternat. Med., 4: 149-163. DOI: 10.1093/ecam/nel117

Brasil, 2007. Ministério da Saúde. RDC N ${ }^{\circ} 67$, de 8 de outubro de 2007. Dispõe sobre boas práticas de manipulação de preparações magistrais e oficinais para uso humano em farmácias.

Brasil, 2008. Presidência da República. Lei N ${ }^{\circ} 11.794$, de 8 de outubro de 2008. Estabelece procedimento para o uso científico de animais.

Brasil, 2011. Farmacopeia Homeopática Brasileira. $3^{\mathrm{a}}$ edição. ANVISA, Brasília.

Brener, Z., 1962. Therapeutic activity and criterion of cure on mice experimentally infected with Trypanosoma cruzi. Rev. Inst. Med. Trop. São Paulo, 4: 389-396. PMID: 14015230

Brener, Z., 1965. Comparative studies of different strains of Trypanosoma cruzi. Ann. Trop. Med. Parasitol., 59: 19-26. PMID: 14297351

Coura, J.R. and J.C. Dias, 2009. Epidemiology, control and surveillance of Chagas disease: 100 years after its discovery. Mem. Inst. Oswaldo Cruz, 104: 31-40. DOI: $10.1590 / \mathrm{S} 0074-02762009000900006$

Dutra, W.O., C.A. Menezes, L.M. Magalhães and K.J. Gollob, 2014. Immunoregulatory networks in human Chagas disease. Parasite Immunol., 36: $377-$ 387. DOI: $10.1111 /$ pim. 12107

Erdmann, H., C. Roßnagela, J. Böhmea, Y. Iwakurac and T. Jacobsd et al., 2013. IL-17A promotes macrophage effector mechanisms against Trypanosoma cruzi by trapping parasites in the endolysosomal compartment. Immunobiology, 218: 910-923. DOI: 10.1016/j.imbio.2012.10.005

Falkowski, G.J.S, C.R Lopes, C.F. Brustolin, P.F. Massini and E.C. Ferreira et al., 2012. Causticum hahnemanni, Conium maculatum and Lycopodium clavatum highly diluted medications decreases parasitemia in mice infected by Trypanosoma cruzi. Int. J. High Dilution Res., 11: 198-199. 
Ferraz, F.N., C.C. Bilotti, D.L. Aleixo, J.C. MartinichenHerrero and A.D. Nascimento Junior et al., 2014a. Hematological and parasitological changes in mice experimentally infected by Trypanosoma cruzi and treated with biotherapy $7 \mathrm{dH}$. Eur. J. Integr. Med., 6: 664-671. DOI:10.1016/j.eujim.2014.07.017

Ferraz, F.N., G.K. Simoni, A. do Nascimento, C.S. de Melo and D.L. Aleixo et al., 2011. Different forms of administration of biotherapy $7 \mathrm{dH}$ in mice experimentally infected by Trypanosoma cruzi produce different effects. Homeopathy, 100: 237-243. DOI: 10.1016/j.homp.2011.05.006

Ferraz, F.N., L. Cipua, F.K. da Veiga, D.L. Aleixo and S.M. de Araujo, 2014b. Medicamento ultradiluído modula a resposta imune e diminui parasitemia em camundongos infectados por Trypanosoma cruzi. Revista de Homeopatia, 77: 60-60.

Galesanu, M., 2014. Tratamento homeopático na tiroidite autoimune: relato de caso. Revista de Homeopatia. 74: 25-27.

Gholamnezhad, Z., M.H. Boskabady and M. Hosseini, 2014. Effect of Nigella sativa on immune response in treadmill exercised rat. BMC Complement. Altern. Med., 14: 437. DOI: 10.1186/1472-6882-14-437

Guedes, P.M., G.K. Silva, F.R. Gutierrez and J.S. Silva, 2011. Current status of Chagas disease chemotherapy. Expert. Rev. Anti Infect. Ther., 9: 609-620. DOI: 10.1586/eri.11.31

Hiyama, K., S. Hamano, T. Nakamura, K. Nomoto and I. Tada, 2001. IL-4 reduces resistance of mice to Trypanosoma cruzi infection. Parasitol. Res., 87: 269-274. DOI: 10.1007/PL00008577

Holscher, C., G. Kohler, U. Muller, H. Mossmann and G.A. Schaub et al., 1998. Defective nitric oxide effector functions lead to extreme susceptibility of Trypanosoma cruzi-infected mice deficient in gamma interferon receptor or inducible nitric oxide synthase. Infect. Immun., 66: 1208-1215. PMID: 9488415

Horta, I., 2012. Estudo prospectivo observacional de uma série de casos de dor osteomusculoarticular crônica com organoterápicos associados ao tratamento homeopático convencional. Revista de Homeopatia, 75: 1-13.

Lorenzi, T.F., 2006. Manual de hematologia: Propedêutica e clínica. $4^{\mathrm{a}}$ edição, Guanabara Koogan, Rio de Janeiro.

Magalhães, L.M., F.N. Villani, M.C. Nunes, K.J. Gollob and M.O. Rocha et al., 2013. High interleukin 17 expression is correlated with better cardiac function in human Chagas disease. J. Infect. Dis., 207: 661-665. DOI: 10.1093/infdis/jis724

Matsuzaki, G. and M. Umemura, 2007. Interleukin-17 as an effector molecule of innate and acquired immunity against infections. Microbiol. Immunol., 51: 11391147. DOI: 10.1111/j.1348-0421.2007.tb04008.x

da Matta Guedes, P.M., F.R.S. Gutierrez, F.L. Maia, C.M. Milanezi and G.K. Silva et al., 2010. IL-17 produced during Trypanosoma cruzi infection plays a central role in regulating parasite-induced myocarditis. PLoS Negl. Trop. Dis., 4: e604- e604. DOI: 10.1371/journal.pntd.0000604
Melo, R.C. and Z. Brener, 1978. Tissue tropism of different Trypanosoma cruzi strains. J. Parasitol., 64: 475-482. DOI: 10.2307/3279787

Miyazaki, Y., S. Hamano, S. Wang, Y. Shimanoe and Y. Iwakura, 2010. IL-17 is necessary for host protection against acute-phase Trypanosoma cruzi infection. J. Immunol., 185: 1150-1157. DOI: $10.4049 /$ jimmunol.0900047

Monteiro, A.C., V. Schmitz, A. Morrot, L.B. de Arruda and F. Nagajyothi et al., 2007. Bradykinin B2 Receptors of dendritic cells, acting as sensors of kinins proteolytically released by Trypanosoma cruzi, are critical for the development of protective type-1 responses. PLoS Pathog., 3: e185. DOI: 10.1371/journal.ppat.0030185

Pérez, A.R., S.D. Silva-Barbosa, L.R. Berbert, S. Revelli and J. Beloscar et al., 2011. Immunoneuroendocrine alterations in patients with progressive forms of chronic Chagas disease. J. Neuroimmunol., 235: 84-90. DOI: 10.1016/j.jneuroim.2011.03.010

Queiroz, A.O., S.C.C. Xavier, K.G. Faria, R.R. Bernardo and T.C.A. Leitão, 2006. Avaliação do bioterápico Trypanosoma cruzi $30 \mathrm{DH}$ : Um estudo in vivo. Cultura Homeopática, 17: 9-13.

Rutitzky, L.I. and M.J. Stadecker, 2006. CD4 T cells producing pro-inflammatory interleukin-17 mediate high pathology in schistosomiasis. Mem. Inst. Oswaldo Cruz, 101: 327-330. DOI: 10.1590/S0074-02762006000900052

Sandri, P., D.L. Aleixo, G.J.S. Falkowski, A.D.N. Júnior and M.L. Gomesemail et al., 2015. Trypanosoma cruzi: Biotherapy made from trypomastigote modulates the inflammatory response. Homeopathy, 104: 48-56. DOI: 10.1016/j.homp.2014.05.007

Silva, J.S., G.N. Vespa, M.A. Cardoso, J.C. Aliberti and F.Q. Cunha, 1995. Tumor necrosis factor alpha mediates resistance to Trypanosoma cruzi infection in mice by inducing nitric oxide production in infected gamma interferon-activated macrophages. Infect. Immun., 63: 4862-4867. PMID: 7591147

Silva, L.H.P. and V. Nussenzweig, 1953. Sobre uma cepa de Trypanosoma cruzi altamente virulenta para camundongo branco. Folia Clin. Biol., 20: 191-208.

Tesmer, L.A., S.K. Lundy, S. Sarkar and D.A. Fox, 2008. Th17 cells in human disease. Immunol. Rev., 223: 87-113. DOI: 10.1111/j.1600-065X.2008.00628.x

WHO, 2015. Chagas disease (American trypanosomiasis). Fact Sheet N³40, World Health Organization.

Zingales, B., S.G. Andrade, M.R. Briones, D.A. Campbell and E. Chiari et al., 2009. A new consensus for Trypanosoma cruzi intraspecific nomenclature: second revision meeting recommends TcI to TcVI. Mem. Inst. Oswaldo Cruz, 104: 1051-1054. DOI: $10.1590 / \mathrm{S} 0074-02762009000700021$ 